\title{
Implications of Changing Attitudes towards Game Meat Consumption at the Time of Ebola in Limbe, Cameroon
}

\author{
Ivo Ngade, Merrill Singer, Olivia Marcus, and Jose Hasemann
}

\begin{abstract}
In this article, we examine social responses to the 2014-2016 Ebola epidemic in Cameroon, a country near to but beyond the farthest reaches of known Ebola cases. As Ebola spread in West Africa, there was mounting anxiety that the epidemic would spill over the border with Nigeria. To investigate people's responses to Ebola-fear, we interviewed a sample of fifty people living in Limbe, near the Nigerian border. We found a pattern of response that involved information-seeking, the adoption of various behavioral strategies believed to protect people from infection, and the spread of messages about Ebola prevention by word of mouth and through social media. Informed by resilience theory and recognition of the emergent nature of culture, we argue that by studying people's emotional, behavioral, and social reactions to perceived health threats, medical anthropologists can contribute to efforts to develop useful intervention in a world of enhanced infectious disease epidemic risk.
\end{abstract}

Key words: Ebola, epidemic fear, resilience theory, mass and social media, "bushmeat" avoidance, Cameroon

\section{Introduction}

$\mathrm{O}$ n May 2, 2016, the final Ebola patient identified by the World Health Organization (WHO 2016) in Liberia from the 2014-2016 epidemic was successfully treated. Sequencing of blood samples from confirmed cases in Guinea and Liberia indicate the source of the virus was from a single and known transmission chain — suggesting

Ivo Ngade is an Andrew Mellon postdoctoral fellow in the Department of Anthropology, Rhodes University in South Africa. He received his Ph.D. from the Department of African Languages and Cultures at Ghent University, Belgium, in 2014. His research domains include HIV-related sexual risk behaviors among youth, technology usage and social relationships, transactional sex, youth culture, and transnational migration. Merrill Singer, a medical and cultural anthropologist, is a Professor in the Departments of Anthropology and Community Medicine at the University of Connecticut. The central focus of his work is the social origins and maintenance of health inequality. His current research focuses on community health impacts of climate change and infectious disease epidemics. Olivia Marcus received her MPH from Columbia University and is currently working toward a Ph.D. in applied medical anthropology at the University of Connecticut. She has done extensive work concerning HIV prevention, health seeking behavior among people living with HIVIAIDS, and sexual health promotion. She is concerned with sustainable intervention design. José E. Hasemann Lara has an MA in anthropology and an MPH in global infectious diseases, both from the University of South Florida. He currently is a doctoral student in anthropology at the University of Connecticut, focusing on citizenship, derogation, urbanization, political ecology, infectious diseases, and public health. His dissertation research is being carried out in Brownsville, Texas, and Tegucigalpa, Honduras, on dengue fever. exposure to infected body fluids from a survivor. Although the WHO continues to assist Sierra Leone in surveillance on the ground, no flare-up cases have been reported. Through April 2016, the West African countries of Guinea, Liberia, and Sierra Leone reported a total of 28,616 confirmed, probable, and suspected Ebola cases and 11,310 Ebola deaths (CDC 2016). Two additional West African countries, Nigeria and Mali, also reported cases during the recent Ebola outbreak, and cases were found in the United States and Europe as well.

It has been hypothesized that the recent Ebola epidemic stemmed from a single zoonotic transmission that did not involve the consumption or even hunting of so-called "bushmeat" (wild game). Saéz et al. (2014) mention that the source of the initial human case appears to have been a colony of insectivore free-tailed bats (Mops condylurus) living in a hollow tree in Meliandou, Guinea. The bats were found by a two-year-old boy, Emile Ouamouno, who was playing in the tree. Emile died of Ebola in December 2013, becoming the index case for the subsequent outbreak. Emile's mother, sister, and grandmother also died of the disease, presumably through human-to-human transmission. From Meliandou, Saéz et al. (2014) believe, the virus spread to people living in other areas of Guinea and then to Sierra Leone, Liberia, and beyond.

One important social impact of the epidemic that has extended beyond those who were infected or directly affected by Ebola was the development of pervasive fear and even panic within African countries and globally (Farmer 2014; Kobayashi et al. 2015). In a survey in Liberia conducted with 609 respondents from five counties, Kobayashi et al. (2015), for example, found that more than 90 percent of respondents 
reported a fear of Ebola patients, over 40 percent indicated they had a fear of cured patients, and over 50 percent acknowledged having a fear of Ebola treatment centers. One cannot justify the conflation of fear of patients and of treatment centers, as the characteristics of fear may differ in different social contexts, but it is evident that the overall level of fear in the general population rose considerably as the epidemic continued. Moreover, there was considerable anxiety among populations in non-affected regions about Ebola spreading to new areas that had not yet reported any cases. In Cameroon, dread became widespread, particularly after Nigeria, with which it shares a long border, experienced eight deaths. Considerable community, mass media, and social media discussion about potential protective strategies circulated in an atmosphere of alarm and uncertainty about the outbreak.

Here, we examine one such strategy that appears to have gained traction in Cameroon: avoiding the consumption of game meat. Game meat, ${ }^{1}$ which includes a range of wild animals (e.g., bats, monkeys, apes, rodents, and other forest animals), is a traditional and culturally meaningful source of protein-rich food in many West African countries. Since the current Ebola outbreak, however, game meat consumption has been cited in the popular media as a cause of the spread of Ebola, a development that seems to be spurring its cultural redefinition as a dangerous source of disease, and hence, as something to be avoided (Hogenboom 2014; IRIN 2014). The science of zoonotic Ebola risk certainly affirms that butchering wild animals (acquiring, opening, dressing, and preparing the carcass) could be a high risk factor for the transmission of bloodborne pathogens because it "involves contact with potentially infected vectors, whereas distant consumption may not" (Wolfe et al. 2005). Consuming wild game is another matter. Nonetheless, field observations by Ngade in border towns in Cameroon suggests a recent and perhaps dramatic decline in game meat consumption at least in part because of the fear that eating wild animals can cause infection. To assess changing attitudes, values, and behaviors concerning game meat consumption, we conducted qualitative interviews among a sample of adult men and women in Cameroon.

Our research addressed the following question: given the high level of distress and even panic triggered by the 20142016 Ebola outbreak and media reports of escalating casualty levels, what were the actual responses in local areas facing this disease threat? Our analysis is framed by social resilience theory (Keck and Sakdapolrak 2013). A resilient social system can absorb disturbances and undergo some degree of change to respond to them (Berkes et al. 2002). By contrast, a rigid system is largely stabilized and resistant to adaptive change. In rigid systems, increasing levels of effort are invested in maintaining existing social patterns. Our research highlights the importance of paying close attention to the ways culture changes - or fails to change - under conditions of mounting stress (Ngade et al. 2016). In other words, the study underlies the importance of resilience. This concept has evolved over time from an initial emphasis on the persistence of ecological systems to include the adaptability of social systems to their changing environments. Adaptability refers to a social system's capacity to adjust and even reorganize in the face of perturbation.

Building on this theoretical perspective, we explore how societies have responded to the threat of Ebola, especially during the prolonged and widespread 2014-2016 epidemic in West Africa. In analyzing our findings, we assess emergent culture as an expression of social resilience. By emergent culture, we mean the appearance of new culturally constructed behaviors, knowledge and values, and emotional reactions. Our objective is to contribute to understanding human social response during an infectious disease epidemic and suggest implications for how changing patterns of game meat consumption affect multiple levels, from consumers, to local hunters, to sellers, to wildlife populations. From an applied perspective, our findings suggest that when health threats are perceived as immediate and personal, change is possible, and further, that social media and text messaging can be an important channel for spreading messages about protecting public health.

\section{Limbe, the Research Site}

Our research was conducted in Limbe, a town near the Cameroon-Nigeria border. Of the Cameroonian cities and towns with proximity to Nigeria, Limbe is of particular interest since it appears that porous trans-border mobility caused local fear of disease spread to be particularly high. Limbe is situated between the Atlantic Ocean and Mount Cameroon. It is a coastal town that attracts tourists, one reason why many restaurants and other food outlets can be found there. Additionally, it is an industrial town hosting the only oil company in Cameroon, called SONARA. The influx of tourists and the booming oil sector in Limbe helped stimulate the supply chain, linking local game hunters and game meat vendors. At least one food market can be found at all of the local venues where data were collected for this study. During the period of our research, dried game meat was not being sold at any of these markets because the sellers were afraid of the government criminalization of the game meat retail sector. Additionally, hunters, who mostly live on the other side of Mount Cameroon, significantly slowed or stopped hunting because of fear of government enforcement of hunting bans issued in response to the epidemic. This is significant because hunting is a source of both food and income for people living near Mount Cameroon. The MIAVITA (2011) study of socioeconomic vulnerability in the Mount Cameroon region found that 39 percent of the population in rural areas of the region is poor, and over 60 percent have no more than a primary school education as compared with 41 percent of urban dwellers in Limbe. About one-third (36\%) of households in rural settings had six or more residents. Primary livelihood activities include farming, unskilled labor, hunting, and fishing. Relatively large family sizes combined with low incomes underlines the nature of the struggle for subsistence in rural communities. Despite these challenges, enhanced government regulation and growing fear of Ebola combined to significantly curtail game meat availability and consumption. 
Talk about Ebola was everywhere in the streets, marketplaces, and other public (and no doubt private) venues in Limbe during the research period. At bus stations, for example, the lead author saw people hurrying in a bid to avoid contact with strangers out of fear of infection. In comparison to the past, when many people would drink in bars along the streets of Limbe, fewer people were in the streets in the evenings. Those who did go to the bars would typically watch TV tuned to programs featuring updates on Ebola. A comment from one bar patron is typical of the conversations that would ensue: "Oh now they said it again on the news, this thing is killing people really, and it's said every day that it is caused by bushmeat." In addition to television, residents also listened to the radio, which featured public service announcements about how to avoid Ebola. One of the main recommendations that was frequently repeated was to avoid eating game meat. This constant exposure to the topic kept Ebola and its alleged connection to game meat fresh in the minds of Limbe residents.

Ngade also observed that people were frequently reminded and warned about Ebola at health centers, churches, and community meetings. For example, outside the Bota Hospital, fliers were posted declaring: "Ebola is real, stop eating bushmeat." People began to refer to eating game meat, literarily, as "eating Ebola." For example, at the bus station, Ngade overhead a man say to his kinsman, "Please go to Batoke [a neighborhood along the mountain in Limbe where most hunters live and hunt], but when you get there be careful not to eat Ebola." Others were heard advising their friends and family to "make sure you eat bitter kola ${ }^{2}$ before going out, as it is the only vaccine we can rely on for now." Parents also warned their children to be careful, especially not to go too close to people they did not know or who might not look well. In short, the topic of Ebola was everywhere on people's lips and minds during the research period, and it was frequently framed within the context of game meat consumption.

\section{Culture and the Consuming of Game Meat}

It is well-established in anthropology that food consumption is rich with cultural meanings (Bourdieu 2010; Douglas 1979; Levi-Strauss 1975). Eating patterns communicate symbolic information about social status and identity, ethnicity, regional attachments, cultural beliefs, values, and wealth. Such meanings are not inherent in food items themselves but are determined by culture and context (Murcott 1982). Of importance to the current study is the strong link between food and identity (Jamal 1998). As Fischler (1988:275) observes, "Any given individual is constructed biologically, psychologically, and socially by the foods he/she chooses to incorporate." In cultural contact situations, for example, two sharply contrasting patterns have been described: preservation of traditional cultural patterns and adoption of new cultural forms. For example, people often "cling desperately to home foods habits" in new situations (Romo and Gil 2012:206).
The cultural significance of dietary choices is noteworthy because "food is one of the most powerful symbols of who we are" (Fox 2008:2) and is central to both personal and cultural identities. Consequently, willingness or unwillingness to change food habits in the context of threat and social disruption is a strong indicator of resilience versus rigidity. Additionally, researchers have described age and gender differences in the symbolic meanings attached to food, and hence, differential willingness to relinquish the consumption of traditional foods (Chapman 1990).

In many parts of sub-Saharan Africa, game meat is commonly eaten as a key source of sustenance in rural areas and often is seen as a favored delicacy in towns and cities. In both locations, it provides a traditional and culturally meaningful source of protein. The extent of the popularity of game meat in West Africa has developed into a multi-billion dollar industry with a significant impact on wildlife populations (Barnes 2002; Brashares et al. 2004). A 2004 public opinion survey conducted in Monrovia, Liberia, found that residents ranked game meat second behind fish as a preferred source of protein, with 80 percent of game meat-consuming households reporting that they cooked it "once in a while," 13 percent said they cooked it once a week, and 7 percent cooked game meat daily (Russell 2014). The survey was conducted during the last civil war, which lasted from 1999 to 2003, and game meat consumption is now believed to be even more common (MacDonald et al. 2011).

The game meat trade in West and Central Africa is a significant commercial industry, with an estimated volume of between one and five million tons per year. Studies in Cameroon indicate that mammals, especially duikers, pygmy antelope, palm squirrels, cane rats, and porcupines, constitute more than 90 percent of game meat sold at market sites ( $\mathrm{Fa}$, Currie, and Meeuwig 2003; Fa, Ryan, and Bell 2004). The number of animals killed for sale is high and the crude biomass extracted from the forests of Cameroon is estimated to be 200 $\mathrm{kg} / \mathrm{km}^{2}$ (Fa, Currie, and Meeuwig 2003). The size of the game meat market among households just for sauce preparation in the capital city of Yaoundé is estimated at \$4 million annually (Wolfe et al. 2005). A recent study of consumption patterns in Cameroon found that game meat plays an important dietary role in lower income households rather than being a luxury food only eaten in wealthier families (Wolfe et al. 2005). A Cameroon market survey before the Ebola epidemic struck West Africa revealed that rodents (e.g., bush-tailed porcupines, pouched rats, and cane rats or grasscutters) comprised the highest percentage of wild animal carcasses in urban markets, with ungulates (e.g., various species of duikers) being relatively less common (MacDonald et al. 2011).

Overall, a staggering volume of wild species is affected by game meat hunting in Cameroon. Indeed, the scale of the game meat trade has made it a significant threat to animal species, particularly primates. Over the last two decades, European and Asian logging companies have built roads into the heart of the last remaining forests in Cameroon. In particular, the mid-1980s construction of the World Bank-funded 
Yaoundé to Douala truck road, as well as the 1992 European Union-supported extension of this road to the border of the timber rich East Province, radically cut the cost of extracting timber and significantly increased access to this area for game meat hunters. Hunters use these roads to reach their prey and transport their kills to urban markets. While the trade in game meat is illegal in Cameroon, the selling of this food in public markets has been openly practiced. Recently, however, the identification of monkeys, gorillas, and bats as reservoirs of the Ebola virus has penetrated public awareness, and there is evidence that fear of game meat as a source of Ebola infection may be impacting people's behavior and leading to a drop in the game meat trade. As will be discussed in our research findings below, the previously open selling of game meat in markets and restaurants is rapidly declining due to decreased consumer demand and a simultaneous crackdown by local and national authorities in response to the Ebola epidemic.

\section{Methods}

The research was conducted in June 2015 in Limbe, Cameroon. Participant observation and interviews took place over a period of three weeks. Participant observation consisted of visiting bars, churches, and other public venues and riding buses. Ngade listened to the conversations taking place around him with special attention for references to Ebola and game meat. The research involved participant recruitment through door-to-door visitation in four neighborhoods in Limbe and on-site, semi-structured interviews that lasted twenty to thirty minutes. The sampling method was purposive based on the willingness of those who were at home to participate. Twenty-three participants were male, and twenty-seven were female, and they ranged in age from nineteen to fifty-seven. The sample size of fifty was selected based on established standards for qualitative interviewing that suggest in a reasonably homogeneous population a high rate of redundancy, and a lack of significant new findings tend to emerge after approximately thirty interviews (Bernard 2000; Morse 2000). We increased the sample size to fifty to ensure we had captured the full range of participant responses and had achieved saturation, and indeed, we began to encounter diminishing returns in our last twenty interviews.

Participants were not paid. Individuals who agreed to participate were asked their preferred and convenient location for the interview (e.g., in their home) where the project was fully explained as part of the informed consent process. No participant names or locations were asked to insure participant anonymity and privacy. Participants were interviewed (using a list of ten core questions, related sub-questions, and improvised questions intended to clarify respondents' answers). Core questions probed familiarity with game meat, life history of game meat consumption, sources of game meat, changing patterns of game meat consumption, awareness and attitudes about the alleged linkage of game meat with the spread of Ebola, involvement in information sharing concerning the association between game meat consumption and Ebola, the adoption of behaviors intended to prevent Ebola, other knowledge/attitudes about Ebola, and experiences with changes in social behavior (including changes in game meat consumption to prevent the spread of Ebola). Field notes were kept on participants' responses for use in data analysis. No interviews were tape recorded. The interviews were conducted in French, English, or "Camfranglais," as desired by the individual participant. Participants were encouraged to speak as fully and extensively as they wished during the interviews. The study protocol for this research was approved by the University of Connecticut's Institutional Review Board (IRB) and Rhodes University Ethical Standards Committee (RUESC).

Content analysis, a method used to make replicable and valid inferences by identifying repeated themes and patterns in textual material was used to scrutinize the data (LeCompte and Schensul 2012, Stemler 2001). This involved reading through each interview and noting responses to the key questions addressed by the study. Similar and differing answers to each question were noted across the fifty participants. General trends in responses are noted below as are answers that differed from the majority response.

\section{Results}

\section{Knowledge of Game Meat and Changing Consumption Habits}

All fifty study participants reported familiarity with the term "bushmeat," and all but one participant reported having eaten it their entire lives. In response to the question, "what does the term bushmeat mean?" participants consistently reported that it is meat from wild animals living in the forest, which suggests that it is a very familiar comestible for the people of Limbe. The single participant who did not grow up eating game meat, a twenty-eight-year-old small business owner, nonetheless begun consuming it within the past five years after marrying her husband, who considered it a delicacy, and both continued to eat it during the outbreak. All of the other participants grew up in a household or village where game meat consumption was common. Recent sources of game meat for these participants included the public markets of Limbe, restaurants, bars, their social networks, or direct access to hunters, including family members.

Of the fifty participants, fourteen did not have to buy game meat because a family member (e.g., parents, uncle, or themselves) hunted and provided game meat for subsistence purposes. Twenty participants reported that they currently or recently obtained game meat directly from hunters (friends, relatives, or contacts) or by hunting themselves (four people), yet even those who had direct connections, found game meat to be so scarce that they could rarely acquire it anymore. For example, one female, a fifty-four-year-old small business proprietor, explained, "My husband brings game meat from the village where he has people, including relatives who hunt in the village." Although this participant reported that she believed game meat could cause Ebola, she did not say she 
avoided eating game meat for this reason. Rather, she stated that the reason she had not eaten game meat in the past several months was because her husband had not been able to find it among the hunters he knew, most likely because they were not hunting as they had in the past. This participant expressed considerable fear of Ebola and reported taking measures such as increased consumption of bitter kola (a nut used traditionally in ethnomedical practice for a range of health problems), showering more often, and making a habit of staying indoors to avoid infection. Among the four participants who reported having hunted for game meat themselves, one of the farmers in our sample, a twenty-three-year-old man, explained that he still eats two wild animals that historically have commonly been consumed as game meat, grass cutters and moles, but is afraid of monkeys, apes, and bats because of Ebola. Participants reported that their consumption practices often changed when they moved to Limbe from natal homes or villages. For example, one man, a fifty-seven-year-old farmer, told us, "When I was in the village, I used to hunt myself, but since I moved to town in Limbe, I buy game meat in the market." Similarly, a forty-year-old woman who ran her own small business explained, "I grew up in a hunter's family...my dad was a farmer and hunter, and game meat was a regular meal in our kitchen back days in the village." Once participants moved to Limbe, these patterns reportedly changed as they began to purchase game meat in public markets or in restaurants.

When asked about frequency of game meat consumption, fourteen participants said they ate game meat regularly or often; twenty-nine reported eating it occasionally, sometimes, or when they could afford it; three said they ate game meat whenever it was available; and three said not at all, although two of these participants had stopped eating game meat years before the current outbreak due to health or religious reasons. The majority of game meat-consuming participants $(62 \%)$ said they stopped or reduced consumption of game meat since the 2014-2016 Ebola outbreak began. Concerning general changes in food consumption habits, twenty-four said they had not made any changes, and eight reported having changed their usual patterns (e.g., ensuring food is well cooked, avoiding game meat from apes and monkeys but eating other kinds of game meat, or knowing the source of the food they eat), but did not report avoiding game meat. Among participants who continued to eat game meat, fourteen reported that scarcity or the increased price of game meat made it difficult or impossible for them to find or consume it. For example, a twenty-three-year-old male student reported that he grew up eating game meat regularly, but because it has become so expensive, he usually only eats it when it is prepared by his mother. Similarly, a female student reported that she only ever eats game meat when her mother cooked it.

Notably, two female participants reported changing their patterns of game meat consumption for reasons unrelated to its association with Ebola transmission. A fifty-nine-yearold fish vendor explained that doctors told her to stop eating game meat in order to resolve a condition she developed in her knees. She noted that if the doctors had not warned her that game meat was causing her knee problems, she would have continued to consume it. This participant expressed an intense fear of Ebola, to the extent that she considered keeping her children home from school in order to ensure their safety, yet she did not think that game meat was a factor in Ebola transmission. The other participant, a twenty-six-year-old student, stopped consuming game meat three years prior to the outbreak in compliance with her new religious practice. Nevertheless, she reported that game meat was a regular part of the diet of her and her family until she was twenty-three, as her father had relationships with hunters.

\section{Sources of Information: Trust, Beliefs, and Behavioral Responses}

We asked participants about their sources of information concerning the association between game meat and Ebola transmission. First, they were asked to specify their sources of information, then if they trusted these sources. Significant sources of information, reported by participants included radio, television, conversations in the market, newspapers, schools, hospitals, and various social gatherings.

The majority of participants (thirty-seven) reported that they trusted their sources of information that told them that game meat can transmit Ebola. However, ten participants (nine males, one female) reported they did not trust the information they received about Ebola and game meat. Their responses included a variety of uncertain answers, including "I trust [my] sources [of] information...concerning Ebola in Liberia, but then I doubt if really game meat can cause Ebola" (fiftyyear-old farmer), and "somehow I do [trust my sources], but then I still can't understand this type of fever" (forty-year-old small business operator). Other responses included "not quite," "unsure," and "somewhat." One participant said that he trusted that Ebola is real, but that consuming game meat does not cause it, and another said he believed his sources at the peak of the epidemic, but as time passed, he changed his mind. In terms of gender, it was notable that only one woman, a thirtyeight-year-old small business owner, reported not trusting her sources of information. Also notable is that ten participants who reported trusting their source of information about Ebola and game meat also reported that they either ate game meat in the past two months or would eat it if it they could find it.

\section{Text Messaging as a Source of Information}

In addition to asking participants to list their sources of information (e.g., media, community, church, etc.), we specifically asked about their text-messaging behaviors. Our interest was in understanding whether people received or sent texts concerning Ebola and game meat consumption and their attitudes or beliefs toward information shared via text. This line of inquiry was precipitated by Facebook messages received by Ngade as he prepared to leave Belgium for Cameroon in September 2014. The day before his departure, a female friend urged him to eat bitter kola while traveling 
from Brussels. She told him that many people in Cameroon, including herself, were buying and stockpiling bitter kola, which they believed could potentially prevent Ebola. When he arrived in Cameroon, he quickly noticed panic about Ebola in the media and on the street and soon discovered that text messages were circulating about possible remedies.

The majority (thirty-eight out of fifty) of participants reported receiving and/or sending text messages that provided information concerning risk and prevention strategies for avoiding Ebola transmission. Many of the initial text messages about the spread of the virus and measures to prevent Ebola were issued anonymously as sms texts sent to subscribers from mobile telephone companies in Cameroon including Mobile Telephone Network (MTN), Orange, and Nextell. Most participants who received such messages (thirty-three of thirty-seven) reported that they forwarded them to friends, relatives, and/or colleagues. Most participants reported receiving a message that warned them that Ebola kills rapidly but can be prevented by avoiding contact, avoiding game meat, washing hands frequently, and eating bitter kola. This message seemingly went viral as people forwarded it to others in their social networks. Some participants sent or received other messages about eating bitter kola and bathing in salt water to prevent Ebola.

Only twelve people in our sample did not send or receive texts concerning Ebola and/or game meat, and two of these individuals explained that they used their partner or children's phone to communicate via text message. An important theme that emerged in text-based information sharing among the other thirty-eight participants was the way in which messages affected attitudes and information seeking behavior. For example, a thirty-three-year-old student reported:

Yes, the messages affected my behavior, particularly about eating game meat or not, and there was a lot of talk about Ebola on TV. It was a very frightening moment, so I had to change my attitude about eating game meat.

When asked if she thought the messages affected others whom she texted, she replied:

I think my messages affected their attitude because some called me and asked if it's true.

The regular use of mobile phones among Cameroonians became common as recently as 2002 (Frei 2013). ColeLewis and Kershaw (2010) suggest that mobile technology not only accelerates the rate of social network development but is also a potentially powerful tool for behavior change for disease prevention and management. This appears to have occurred at the popular level with the Ebola epidemic.

\section{Recent Consumption, Scarcity, and Skepticism}

Most participants (thirty-nine) had not consumed game meat within the past two months, five of these cited scarcity as a main reason, although thirty of them believed that Ebola may be transmitted through game meat. Importantly, five of these thirty expressed belief with a degree of skepticism, such as wondering if it is a myth or, more conspiratorially, speculating that only animals injected by scientists spread Ebola.

Among the eleven participants who reported eating game meat within the past two months, six stated the belief that Ebola may be transmitted through game meat. One of these participants, a female veterinarian, had stockpiled game meat from the market before it became scarce, which allowed her to continue eating it when others could not find it. Interestingly, she explained that Ebola was transmitted through gorillas and monkeys, and that she had sent text messages to siblings, colleagues, and friends telling them to avoid eating game meat. This is just one example of a participant who exhibited seemingly inconsistent attitudes and behaviors toward game meat consumption. Another example, a thirty-two-year-old soldier, reported eating game meat a few times while also forwarding texts to friends, relatives, colleagues, and even his commander to avoid game meat, among other preventive strategies (e.g., using medicated soap, taking salt water baths, and eating bitter kola).

In a recent report on public perceptions and Ebola outbreak response in Liberia, Mukpo (2015) observed that his informants exhibited a general trust in radio, family, and religious sources of information rather than governmental (local or national) sources. Importantly, he also found that "[d]enial of the disease was fueled by mistrust towards government, which was only reduced when people saw visual evidence of Ebola or heard firsthand accounts from trusted sources," such as radio or word of mouth in the community (Mukpo 2015:25). Our data exhibit a similar pattern, namely, participants' beliefs that Ebola was manufactured and injected into animals for testing, or as one participant asserted, Ebola is a strategy used to conserve wildlife by stopping hunters from killing animals.

Of the thirty-five participants who reported that they believed game meat can cause Ebola, only nineteen stated that they stopped eating it since the 2014 explosion in fear of transmission. Other reasons for not eating game meat included scarcity in the markets, inability to find hunters who will hunt for game meat, and the increased prices for game meat. Significantly, despite reporting positive attitudes toward their information sources, strong beliefs in the dangers of eating certain types of meat, and a strong fear of Ebola transmission, almost half of our respondents did not change their consumption habits to exclude game meat. However, a few participants did explain that they now pay more attention to the source of their food and must check to ensure it is well cooked.

The remaining fifteen participants had more skeptical beliefs about the role of game meat in Ebola transmission: one female respondent, a farmer and small business owner, believed that game meat could spread Ebola but also wondered if this might be a myth:

Yes, I think so [that game meat causes Ebola], but sometimes I wonder where this is coming from, especially as we grew up eating bush as a regular meal and nothing happened. But now there is so much talk about Ebola and 
game meat.... Yes, I think it is [a myth] because it's not normal.... If my grandparents were still alive, they won't want to hear that someone stopped eating game meat because it was something they ate throughout their lives.

The connection between game meat consumption and ancestral eating habits was important for several of the participants. For example, a fifty-nine-year-old female farmer and fish vendor posed the question: "I have been wondering sometimes about the reality of such a terrible disease and why it comes through animals that our forefathers have been consuming for centuries with no problem." A male development worker also reflected on this social history, telling us that his ancestors had proven that meat from the forest was not a problem and that only young people can be deceived by such ideas.

In addition to belief in the value of positive familial experience with game meat, as suggested, some participants expressed conspiratorial understandings of Ebola. For example, a forty-one-year-old male taxi driver opined that game meat can cause Ebola but not naturally; only animals on which Ebola has been tested will spread the disease. A similar sentiment was repeated by another man, a thirty-eight-year-old surveyor who said that Ebola was fabricated by scientists, therefore only game meat intentionally injected with the virus will cause Ebola. One man, a small business owner, expressed the belief that illnesses were tested on animals in affected countries, therefore animals in Cameroon, where such testing was not done, were safe. When asked if he believed that game meat causes Ebola, this individual answered:

Not really, otherwise I won't be still eating. Instead, I think Ebola was tested in Guinea and Liberia. If it reaches in Cameroon, then it's through someone from those countries but not because of our game meat here, no.

Another participant, a soldier, similarly stated that "I don't trust the sources. I think Ebola is produced from the lab, it's a lab test."

Attitudes and behaviors toward consuming game meat were highly associated with age and social context, even when substantial fear of Ebola was discussed. All but one participant between nineteen and thirty-five years of age explicitly stated a belief that game meat can cause Ebola and also indicated their trust in the sources of information as well as their support for recent avoidance of game meat consumption. In contrast, participants who refuted that game meat may cause Ebola were all thirty-eight years or older. The lone exception was the woman who only recently begun consuming game meat after her marriage. The likely reason for such age-related differences in responses is that younger participants (nineteen to thirty-five years of age) had more years of formal education, were likely more involved with social media, and were less traditionally oriented than those above the age of thirty-five. Older game meat consumers may be more inclined to look to their ancestors as a model for contemporary behavior and attribute contemporary calamities to modernity, technological advancement, or Western influences. In this sense, the idea held by some of our older participants, and encountered during participant observation, that Ebola was created in a laboratory in America and brought for testing in Africa, might be understood as an expression of discomfort with Western cultural and economic intrusion into Cameroonian society. Notably, in her fieldwork in Liberia, Tankink (2015) found that many of her informants referred to angry ancestors to explain the current epidemic.

\section{Prevention Strategies: Science, Tradition, and Religion}

The most commonly reported prevention strategies included avoiding game meat consumption, avoiding contact, washing hands, bathing in salt water, and eating bitter kola. In addition, some participants referred to religious practices as a form of prevention. One man, who worked with the National refining company (SONARA Limbe), for example, related, "I don't eat game meat, I eat bitter kola and wash hands several times and even pray to God." A worker with the Cameroon Development Cooperation (CDC Bota) said that he does not practice these prevention strategies, rather, "I just live and believe the ancestors will never allow this to happen to us."

Although religious beliefs were not asked of participants, spiritual and religious practices played an important role in the 2014-2016 Ebola outbreak. Customs, such as carefully washing Ebola-infected bodies before burial, helped to rapidly transmit Ebola among relatives and friends. While ethno-religious alternatives such as bathing in salt water, bathing in water blessed by a priest, or praying to ancestors for protection can pose a health threat if they serve as a replacement to effective disease-prevention interventions (e.g., handwashing, reporting symptoms, avoiding contact), it is important to understand the value of spiritually and culturally meaningful practices within communities affected by the epidemic. For example, in the second-largest outbreak of Ebola, which occurred in Uganda in 2001, Kinsman (2012) observed that religion was an important source of support and perceived protection. Indeed, in the first thirty days of an Ebola outbreak that occurred in 2012 in Uganda, a congregation of 300 Christian churches met in Kampala to pray for an end to Ebola, while both Christian and Muslim religious leaders interpreted the outbreak as divine retribution for personal or national sins, a sentiment that was commonly repeated during the 2014-2016 epidemic (Kinsman 2012).

On the one hand, religiously-based interventions and interpretations of this nature may pose a public health threat in terms of gathering hundreds of people together during an infectious epidemic or relying on supernatural appeals in lieu of evidencebased prevention strategies. On the other hand, Bah and Aljoudi (2014) note that religious beliefs can provide a very important point of intervention for raising awareness and changing potentially harmful behaviors. Among Muslim-majority communities, for instance, a close interpretation of the Hadith concerning how people should react in times of pestilence could instigate behavioral changes if supported by local religious leaders (Bah and 
Aljoudi 2014). Religious institutions have provided "key social roles and contributions to resilience and peacebuilding during lengthy conflicts" in the current Ebola-affected countries, and it is likely that delays in appreciating "the vital roles of religious actors in addressing Ebola and supporting health systems" was detrimental to slowing the epidemic in its initial stages (Marshall and Smith 2015:1). Faith-based initiatives and organizations effectively responded to the epidemic by providing health care, training pastors, mobilizing volunteers, spreading health messages via text to congregations, and caring for orphans (Marshall and Smith 2015).

\section{Discussion}

The threat of Ebola spreading into Cameroon galvanized widespread responses by government, communities, and individuals. The government implemented more stringent enforcement against game meat hunters and game meat selling, as well as the dissemination of health messages linking game meat with Ebola transmission. The criminalization of hunting wild animals in Cameroon is overseen by the Ministry of Forests and Wildlife. The Ministry is responsible for implementing international conventions ratified by Cameroon regarding wildlife and hunting, such as the Forestry, Wildlife, and Fisheries Law of 1994, as well as subsequent related decrees and orders of the Prime Minister of Cameroon (DLA Piper 2014). Penalties for violations of the various wildlife protection laws include both monetary fines and/or incarceration. The Ministry has the authority to settle violations by "transaction," which involves imposing a monetary fine without a court hearing. Such "transactions" are often viewed as a source of corruption (Nguiffo and Talla 2010).

The country's hunting laws were not developed because of the health risk of Ebola but rather as part of an effort to conserve biodiversity in collaboration with international conservation groups. Before the 2014-2016 Ebola epidemic, the actual rate of prosecution was quite low, and the penalties that were imposed did not have a deterrent effect on hunting activities. Moreover, hunting was permitted for those who were granted a hunting licence by the Ministry (as specified in Section 34 of the 1995 Decree). But many hunters in Cameroon generally, like those in Limbe, did not attempt to obtain a hunting license because it required paying a hunting tax which was seen as prohibitively expensive. They believed that if they paid the tax, there would not be much money left from the sale of game meat to support their families. Many preferred to hunt illegally, mostly at night when they would be least likely to be discovered by forest guards. When they were caught, hunters often offered some of their catch to the guards to gain their release. When Ebola began to be associated with game meat consumption, forest guards would no longer accept such bribes because they feared infection. During the Ebola outbreak, the Ministry of Health reinforced this fear by issuing pronouncements about the risks of game meat. As a result of these changes, the rate of hunting appears to have dropped drastically.
At the community level, churches, social groups, schools, social networks, and media rapidly spread information via text message and by word of mouth (Palen and Liu 2007). At the individual level, decisions to pass on important health information, verify or seek out further information, and refrain from game meat consumption or modify eating habits marked a rapid change in response to the rising threat of the epidemic. The majority of our participants (twenty-nine out of forty-seven game meat-consuming participants) either reduced or abstained from eating game meat in response to the 2014-2016 outbreak. Reduction or abstention from game meat consumption occurred for a variety of reasons, namely fear of Ebola, scarcity in the markets or restaurants, and a decrease in hunting practices. Nevertheless, when goods are scarce, this may create invisible markets (away from the public markets in Limbe), which may push the price up, and so game meat consumers might still be able to find game meat for sale but at exorbitant cost.

In an atmosphere of fear and uncertainty, the participants in our study displayed a tendency toward resilient action. Over the last half century, the concept of resilience has emerged in many disciplines, including anthropology, to address diverse forms of social and ecological disasters and threats to health and well-being (Folke 2006; Rogers 2013). Commonly, resilience is defined as the ability of a system to undergo change while still retaining its overall structure (Walker et al. 2004). The notion of resilience is contrasted with stabilized rigidity. A resilient system can absorb disturbances and undergo some degree of modification to respond to them (Berkes et al. 2002). A stabilized or rigid system is fixed and tends to be resistant to adaptive change. In such systems, more and more effort is invested in maintaining social patterns as they are currently organized. The most dangerous form of stabilization is known as "the rigidity trap" and involves strong resistance to novelty, innovation, and change despite increases in human disease, suffering, and death (Gunderson and Holling 2002). Building on this theoretical perspective, we have sought to better understand how societies have responded to the threat of Ebola, especially during the prolonged and widespread 2014-2016 epidemic in West Africa. Given the high level of fear and even panic described for some locales in the midst of an Ebola outbreak (Evans 2014), what were the actual onthe-ground responses in local areas facing the threat of Ebola? Would they best be described as instances of resilience, or are they best characterized as culturally constructed rigidity traps (e.g., exhibiting persistent adherence to pre-existing cultural practice in the context of external threat)? We found that most of our study participants were willing to alter their eating and other lifestyles by, for example, changing social interaction practices, consuming bitter kola, and adapting their hygiene practices. Regardless of the efficacy of these interventions, people responded to the situation and acted on the best information they had. Our findings suggest that the people around Limbe were not passive actors when facing the threat of an Ebola outbreak. Instead, they were actively engaged in sharing information and altering their lifestyles to ensure 
the well-being of themselves, their families, and friends. In this process, new cultural forms emerged or older ones were recast to respond to perceived threat and vulnerability.

Of equal importance was the method of action, which exhibited a high degree of resilience in terms of altering game meat consumption and hunting practices while supporting others, such as community engagement through information sharing and text messaging. Although there were a number of participants who did not believe that game meat could transmit Ebola and did not willingly change their game meat eating habits, almost all reported other behavioral changes such as increased consumption of bitter kola or staying indoors. In addition, it is important to observe the reasons that some participants may have exhibited more rigid behavioral patterns (e.g., continuing to eat game meat despite believing it could transmit Ebola or rejecting information about game meat as a threat and continuing to eat it if possible). When probed for their attitudes and beliefs, many did not believe that Ebola was a threat to Cameroon at the moment, or they believed that the threat lay with government-led schemes involving scientific experiments or environmental conservation. Skepticism in this regard is understandable considering longstanding issues with political corruption and the involvement of multi-national companies in environmental degradation (Ndedi and Mua 2015).

One consequence of the changes described above is the loss of a livelihood source among game meat hunters and sellers who now find themselves at an economic disadvantage because of the dramatic reduction in demand and availability of their products, as well as the increased enforcement of game meat hunting laws. Several participants noted that the game meat market has crumbled, and two male participants voiced concern over the decrease in economic subsistence related to game meat consumption, noting that many women - often widows and single mothers - rely on participation in the game meat market for their income.

In the context of Cameroon, effective engagement with religious leaders and institutions may be important for reducing fear, stigma, and the spread of misinformation as people consider and react to the threat of Ebola in the future. Churches and religious groups were a common source of information concerning Ebola prevention and, importantly, are often well-trusted by members and congregants. It is imperative that public health programs establish relationships and good communication with religious and spiritual groups, both small and large, in order to assist the dissemination of accurate and helpful public health information.

\section{Limitations of the Research}

There were several limitations to our research. The first is that our understanding about game meat scarcity stemming from reduced hunting is based on interviews with non-hunters. Interviews with hunters around Limbe community would have given us more data to demonstrate a correlation between the Ebola epidemic and reduced game meat consumption. This work is planned for a subsequent project. Another limitation is that Limbe is quite urban, and our research does not address what was happening in rural areas of the country. Government officers who enforce regulations are more visible in towns than in villages. Therefore, hunters who live in more rural villages are more likely to hunt successfully despite enforcement as compared to those living around Limbe. Another limitation is that religion was not included in the demographic data collection, and we only realized the importance of this issue midway through our research when two participants reported that they had stopped eating game meat years before the current outbreak due to health and religious reasons.

\section{Conclusion}

Behavioral strategies among our participants were not uniform; different people with different histories responded in distinct ways, yet faced with the spread of a greatly feared - and little understood-epidemic, Cameroonians were not stuck in a cultural rigidity trap. The participants sought out information; spread health messages among their social networks; and adopted various behavioral strategies to protect themselves, family, friends, and colleagues from infection. Some were clearly convinced that game meat could not naturally transmit such a deadly disease because it had not done so in the past. While experience is a critical influence on everyone's behavior, it is necessary to build an understanding that in a world of infectious agents, new diseases do emerge in human populations, and previously safe behaviors can become routes of disease transmission. This is a key public health message that warrants broad dissemination. It is also vital to recognize that people will act in the face of a perceived emergency, and thus, public health and applied medical anthropology responses must take into account shifting, rather than fixed, behavioral patterns in order to create feasible and meaningful messages and interventions. There is little doubt that there will be future Ebola outbreaks as well as outbreaks of other new and old zoonotic diseases in human populations in this region. Effective responses require awareness of what is happening on the ground in communities, a well-known capacity of medical anthropology, and this awareness must be coordinated with planned initiatives at the levels of NGO, government, and international aid. Based on local, on-theground research, anthropologists can help shape the kinds of messages that may have the greatest effect in contexts of fear and a growing sense of vulnerability.

One unintended consequence of Ebola epidemics, and the belief that game meat consumption may be a route of infection among humans, is a reduction of hunting pressure on forest wildlife. Various analyses suggest that the game meat trade has a severe impact on species that are vulnerable to overexploitation. For some species, like gorillas, that are at severe risk for Ebola infection, declines in game meat hunting activity "may not be enough to prevent extinction if frequent outbreaks occur" (Rizkalla, BlancoSilva, and Gruver 2007). For other species, including rodents, 
ungulates, pangolins, reptiles, birds, and mammalian carnivores, Ebola-triggered reductions in game meat consumption and enhanced enforcement of wildlife hunting bans may be diminishing the offtake burden on wildlife and reducing the risk of population collapse and extinction, an issue in need of further study (MacDonald et al. 2011). Ethnographic research on food procurement behaviors, especially in forested and agricultural areas near cities, can contribute the kind of contextualized behavioral data needed to insure wildlife and human sustainability.

\section{Notes}

${ }^{1}$ Commonly referred to as bushmeat, the term game meat is used here to avoid the stereotyping of meat from hunted as opposed to domestic animals in developing countries (Oduntan, Soaga, and Jenyo-Oni 2012) as well as what Seay and Dione (2014) refer to as the long and ugly tradition of treating Africa as dirty and diseased.

${ }^{2}$ Garnicia kola is a fruit seed from a garnicia plant purported to treat Ebola (see Iwu, Diop, and Okunji 1999).

\section{References Cited}

Bah, Sulaiman, and Abdullah Aljoudi

2014 Taking Religious Perspective to Contain Ebola. Lancet 384(9947):951.

Barnes, Richard

2002 The Game Meat Boom and Bust in West and Central Africa. Oryx 26(2):236-242.

Berkes, Fikret

2002 Cross-scale Institutional Linkages: Perspectives from the Bottom Up. In The Drama of the Commons. Elinor Ostrom, Thomas Dietz, Nives Dolsak, Paul C. Stern, Susan Stonich, and Elke Weber, eds. Pp. 293-322. Washington, D.C.: National Academy Press.

Bernard, Harvey

2000 Social Research Methods. Thousand Oaks, CA: Sage.

Bourdieu, Pierre

2010 Distinction: A Social Critique of the Judgement of Taste. Abington, Oxon, United Kingdom: Taylor and Francis.

Brashares, Justin, Arcese, Peter, Sam, Moses, Coppolillo, Peter, Sinclair, A., and Andrew Balmford

2004 Bushmeat Hunting, Wildlife Declines, and Fish Supply in West Africa. Science 306(1180):1180-1183.

Centers for Disease Control and Prevention (CDC)

20162014 Ebola Outbreak in West Africa-Case Counts. URL:<http://www.cdc.gov/vhf/ebola/outbreaks/2014-westafrica/case-counts.html $>$ (May 28, 2016).

Chapman, Malcolm

1990 The Social Definition of Want. In Food for Humanity: Crossdisciplinary Readings. Malcolm Chapman and Helen Macbeth, eds. Pp. 26-34. Oxford Polytechnic, Oxford, United Kingdom: Centre for the Science of Food and Nutrition.

Cole-Lewis, Heather, and Trace Kershaw

2010 Text Messaging as a Tool for Behavior Change in Disease Prevention and Management. Epidemiological Reviews 32(1):56-69.
DLA Piper

2014 Empty Threat: Does the Law Combat Illegal Wildlife Trade? An Eleven-Country Review of Legislative and Judicial Approaches. URL: $<$ http://www.dlapiperprobono.com/ export/sites/pro-bono/downloads/pdfs/Illegal-Wildlife-TradeReport-2014.pdf $>$ (May 29, 2016).

Douglas, Mary

1979 Purity and Danger: An Analysis of Concepts of Pollution and Taboo. New York: Routledge.

Evans, Carter

2014 Ebola Panic Spreading Much Faster Than Disease in U.S. URL:<URL:http://www.cbsnews.com/news/ebola-panic-in-usspreading-much-faster-than-disease/> (June 1, 2015).

Fa, John, Dominic Currie, and Jessica Meeuwig

2003 Game Meat and Food Security in the Congo Basin: Linkages between Wildlife and People's Future. Environmental Conservation 30(1):71-78.

Fa, John, Sarah Ryan, and Daniel Bell

2004 Hunting Vulnerability, Ecological Characteristics, and Harvest Rates of Bushmeat Species in Afrotropical Forests. Biological Conservation 121(2):167-176.

Farmer, Paul

2014 Diary. London Review of Books 36(20):38-39.

Fischler, Claude

1988 Food, Self, and Identity. Social Science Information 27(2):275-293

Folke, Carl

2006 Resilience: The Emergence of a Perspective for Social-Ecological Systems Analysis. Global Environmental Change 16(3):253-267.

Fox, Robin

2008 Food and Eating: An Anthropological Perspective. URL:<www.sirc.org/publik/foxfood.pdf> (June 3, 2015)

Frei, Bettina

2013 Sociality Revisited? The Use of the Internet and Mobile Phones in Urban Cameroon. Oxford, United Kingdom: African Books Collective.

Gunderson, Lance, and Crawford Stanley Holling

2002 Panarchy: Understanding Transformations in Human and Natural Systems. Washington, D.C.: Island Press.

Hogenboom, Melissa

2014 Ebola: Is Game Meat behind the Outbreak? URL:<http:// www.bbc.com/news/health-29604204> (July 2, 2015).

IRIN

2014 West Africa - Ebola and the Bush Meat Connection. URL: $<$ http://africajournalismtheworld.com/tag/ebola-and-bushmeat $/>$ (June 2, 2015).

Iwu, Maurice, D. Diop, and Chris Okunji

1999 New Antimicrobials of Plant Origin. In Perspectives on New Crops and New Uses. Jule Janick, ed. Pp. 457-462. Alexandria, VA: American Society for Horticultural Science Press.

Jamal, Ahmad

1998 Food Consumption among Ethnic Minorities: The Case of BritishPakistanis in Bradford, UK. British Food Journal 100(5):221-227. 
Keck, Marcus, and Patrick Sakdapolrak

2013 What is Social Resilience? Lessons Learned and Ways Forward. Ekdkunde 67(1):5-19.

Kinsman, John

2012 "A Time of Fear": Local, National, and International Responses to a Large Ebola Outbreak in Uganda. Globalization and Health 8(15):1-12.

Kobayashi, Miwako, Karlyn Beer, Adam Bjork, Kevin ChathamStephens, Cara Cherry, Sampson Arzoaquoi, Wilmot Frank, Odell Kumeh, Joseph Sieka, Adolphus Yeiah, Julia E. Painter, Jonathan Yoder, Brendan Flannery, Frank Mahoney, and Tolbert Nyenswah

2015 Community Knowledge, Attitudes, and Practices Regarding Ebola Virus Disease-Five Counties, Liberia, SeptemberOctober, 2014. Morbidity and Mortality Weekly Report 64(26):714-718.

LeCompte, Margaret, and Jean Schensul

2012 Analysis and Interpretation of Ethnographic Data: A Mixed Methods Approach. Lanham, MD: Altamira Press.

Levi-Strauss, Claude

1975 The Raw and the Cooked. New York: Harper and Row.

MacDonald, David, Paul Johnson, Lise Albrechtsen, Aadam Dutton, Arah Seymour, Jeff Dupain, Amy Hall, and John Fa

2011 Association of Body Mass with Price of Game Meat in Nigeria and Cameroon. Conservation Biology 25(6):1220-1228.

Marshall, Katherine, and Sally Smith

2015 Religion and Ebola: Learning from Experience. The Lancet. DOI: http://dx.doi.org/10.1016/S0140-6736(15)61082-0.

\section{MIAVITA}

2011 The MIAVITA Socio-economic Vulnerability Study on Mount Cameroon Region. URL:<http://miavita.brgm.fr/pressroom/ Pages/socio-economicvulnerabilitystudy.aspx $>$ (July 20, 2016).

Morse, Janice

2000 Determining Sample Size. Qualitative Health Research $10(1): 3-5$

Mukpo, Ashoka

2015 Surviving Ebola: Public Perceptions of Governance and Outbreak Response in Liberia. International Alert. URL:<http://www.international-alert.org/sites/default/files/ Liberia_SurvivingEbola_EN_2015.pdf $>$ (July 22, 2015).

Murcott, Anne

1982 The Cultural Significance of Food and Eating. Proceedings for the Nutrition Society 41(2):203-210.

Ndedi, Alain, and Kelly Kingsley Mua

2015 Challenges Facing the Fight against Fraud and Corruption Practices in the Cameroonian Public Sector. URL: $<$ https://ssrn. com/abstract $=2559000>($ April 5, 2016)

Ngade, Ivo, Merrill Singer, Olivia Marcus, and Jose Hasemann

2016 Washing Away Ebola: Environmental Stress, Rumor, and Ethnomedical Response in a Deadly Epidemic. In A Companion to the Anthropology of Environmental Health. Merrill Singer, ed. Pp. 157-172. San Francisco, CA: Wiley-Blackwell.

Nguiffo, Sameul, and Marius Talla

2010 Cameroon's Wildlife Legislation: Local Custom Versus Legal Conception. Unasylva 236(61):14-18.
Oduntan, O., Jubril Soaga, and Adetola Jenyo-Oni

2012 Comparison of Edible Frog (Rana esculanta) and Other Bush Meat Types: Proximate Composition, Social Status, and Acceptability. Journal of Environmental Research and Management 3(7):124-128.

Palen, Leysia, and Sophia Liu

2007 Citizen Communications in Crisis: Anticipating a Future of ICT-supported Public Participation. Proceedings of the SIGCHI Conference on Human Factors in Computing Systems. New York: Association for Computing Machinery.

Rizkalla, Carol, Francisco Blanco-Silva, and Stephanie Gruver 2007 Modeling the Impact of Ebola and Game Meat Hunting on Western Lowland Gorillas. EcoHealth DOI: 10.1007/s10393007-0096-2.

Rogers, Peter

2013 Rigidity Trap in Global Resilience: Neoliberalism Through Principles, Standards, and Benchmarks. Globalization 10(3):389395.

Romo, Rodrigo, and José Gil

2012 Ethnic Identity and Dietary Habits among Hispanic Immigrants in Spain. British Food Journal 114(2):206-223.

Russell, Wynfred

2014 Extinction Is Forever: A Crisis That Is Liberia's Endangered Wildlife. URL: $<$ http://www.frontpageafricaonline.com/index. $\mathrm{php} / \mathrm{op}$-ed/commentaries-features/380-extinction-is-forever-acrisis-that-is-liberia-s-endangered-wildlife > (June 2, 2015).

Saéz, Almudena, Sabrina Weiss, Kathrin Nowak, Vincent Lapeyre, Fee Zimmermann, Ariane Düx, Hjalmar S. Kühl, Moussa Kaba, Sebastien Regnaut, Kevin Merkel, Andreas Sachse, Ulla Thiesen, Lili Villányi, Christophe Boesch, Piotr W. Dabrowski, Aleksandar Radoni, Andreas Nitsche, Siv Aina J. Leendertz, Stefan Petterson, Stephan Becker, Verena Krähling, Emmanuel Couacy-Hymann, Chantal Akoua-Koffi, Natalie Weber, Lars Schaade, Jakob Fahr, Matthias Borchert, Jan F. Gogarten, Sébastien Calvignac-Spencer, and Fabian H. Leendertz

2014 Investigating the Zoonotic Origin of the West African Ebola Epidemic. EMBO Molecular Medicine 7(1):17-23.

Stemler, Steve

2001 An Overview of Content Analysis. Practical Assessment, Research, and Evaluation 7(17).

Tankink, Marian

2015 Introduction to the Special Section on Ebola: Reflections from the Field. Intervention 13(1):45-48.

Walker, Brian, Crawford Stanley Holling, Stephen R. Carpenter, and Ann Kinzig

2004 Resilience, Adaptability, and Transformability in Social Systems. Ecology and Society 9(2):5.

Wolfe, Nathan, Peter Daszak, A. Marm Kilpatrick, and Donald Burke 2005 Game Meat Hunting, Deforestation, and Prediction of Zoonotic Disease. Emerging Infectious Disease 11(12):18221827.

World Health Organization

2016 2016: Top Stories on the Ebola Outbreak. URL:<http://www. who.int/csr/disease/ebola/top-stories-2016/en/> (May 30, 2016). 